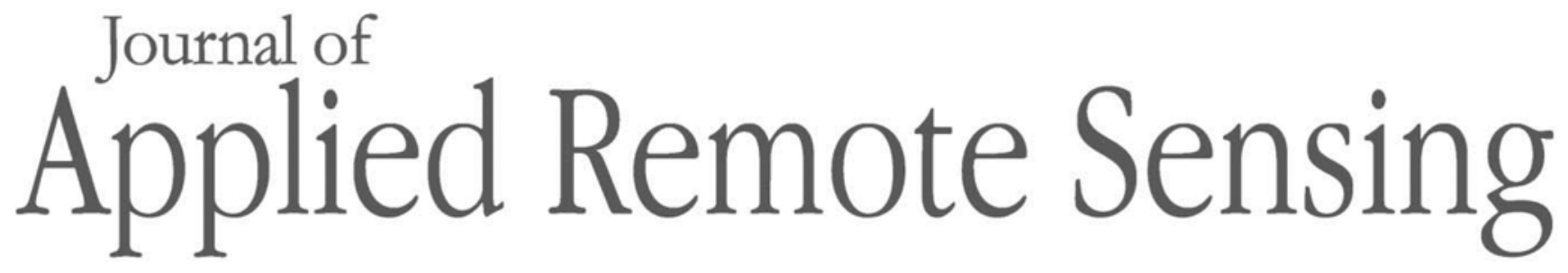

RemoteSensing.SPIEDigitalLibrary.org

\title{
Algorithms for the classification and characterization of aerosols: utility verification of near-UV satellite observations
}

Sonoyo Mukai

Itaru Sano

Makiko Nakata 


\title{
Algorithms for the classification and characterization of aerosols: utility verification of near-UV satellite observations
}

\author{
Sonoyo Mukai, ${ }^{a, *}$ Itaru Sano, ${ }^{\text {b }}$ and Makiko Nakata ${ }^{b}$ \\ ${ }^{a}$ Kyoto College of Graduate Studies for Informatics, Kyoto, Japan \\ ${ }^{\mathrm{b}}$ Kindai University, Higashi-Osaka, Japan
}

\begin{abstract}
Aerosol types were characterized and classified using multispectral satellite data. The role of near-UV data in the detection of absorbing aerosols, such as biomass burning aerosols (BBA) or mineral dust particles (DUST), was examined on a global scale. An absorbing aerosol index (AAI) was proposed and defined as the ratio of the satellite-observed radiance $(R)$ at a wavelength of $0.412 \mu \mathrm{m}[R(0.412)]$ to that at $0.380 \mu \mathrm{m}[R(0.380)]$ that can also detect nonabsorbing-type aerosols. Initially, the numerical AAI values were estimated for the BBAs and DUST from measurements collected by the Advanced Earth Observing Satellite-2/Global Imager (ADEOS-2/GLI). The Japanese short mission ADEOS-2 carried the GLI instrument with observation channels in the near-UV region. Not only the AAI index but also the short-wavelength infrared measurements were utilized to determine the dust detection index (DDI) defined as the ratio of $R(2.210)$ to $R(0.380)$ in order to discriminate BBAs from DUST. In addition, the AAI and DDI values were evaluated for the detection of clouds. The results allowed the classification criteria for DUST, BBA, other types of aerosols and clouds to be obtained. The Second-Generation Global Imager (SGLI) sensor is onboard the Japanese Global Change Observation Mission-Climate (GCOM-C) (SHIKISAI in Japanese) satellite launched on December 23, 2017. The SGLI has multiple channels (19) including near-UV and polarization sensors in the red and near-IR wavelengths. We also demonstrated the advantages of the SGLI for near-UV and polarization data for aerosol remote sensing. An understanding of aerosol types facilitated subsequent aerosol retrieval. Then, retrieval for classified aerosols was made based on the radiation simulations with multispectral radiance by GLI and polarization measurements by Polarization and Directionality of the Earth's Reflectances (POLDER)-2, respectively, mounted on the ADEOS-2 satellite. The proposed algorithms are expected to be available not only for the analysis of the SGLI data but also for other future missions. () The Authors. Published by SPIE under a Creative Commons Attribution 4.0 Unported License. Distribution or reproduction of this work in whole or in part requires full attribution of the original publication, including its DOI. [DOI: 10.1117/1.JRS.13 .014527]
\end{abstract}

Keywords: advanced earth observing satellite-2/global imager; global change observation mission-climate/second-generation global imager; color ratio; biomass burning aerosols; mineral dust particles.

Paper 190019 received Jan. 12, 2019; accepted for publication Mar. 5, 2019; published online Mar. 19, 2019.

\section{Introduction}

Global Change Observation Mission-Climate (GCOM-C) satellite was successfully launched on December 23, 2017, equipped with the multispectral Second-Generation Global Imager (SGLI). The SGLI has 19 channels that encompass the near-UV $(0.380 \mu \mathrm{m})$ and violet $(0.412 \mu \mathrm{m})$ wavelengths, and two polarization channels in the red $(0.674 \mu \mathrm{m})$ and near-IR $(0.869 \mu \mathrm{m})$ wavelengths. The motivation for this study was to develop effective aerosol retrieval algorithms by utilizing the features of the GCOM-C/SGLI. The goal was not only to develop these tools for the analysis of the SGLI data but also for future missions.

It is known that atmospheric aerosols impact the environment and climate change by directly absorbing and/or scattering solar radiation. This occurs by indirect modification of the optical

*Address all correspondence to Sonoyo Mukai, E-mail: s_mukai@kcg.ac.jp 
properties and lifetimes of clouds, as well as by influences on the meteorology. ${ }^{1}$ Nevertheless, the characteristics and distribution of atmospheric aerosols are complicated, owing to both natural factors and human activities. Given these effects, determining accurate estimates of aerosol properties and emissions is an increasingly urgent subject to understand global climate problems. For example, forest fires have increased due to global warming and climate change. The fifth Intergovernmental Panel on Climate Change (IPCC) report ${ }^{2}$ emphasized the importance of observing aerosol characteristics and their temporal and spatial variations, indicating the warming effect of black carbon aerosols versus the cooling effect of other aerosol types. Aerosol distributions vary seasonally due to many factors such as emissions, photochemical reactions, and wind direction. ${ }^{3,4}$ Hazardous air pollution events remain insufficiently understood. Moreover, in urban areas, increasing amounts of small anthropogenic particle emissions are causing an increase in the concentrations of harmful air pollutants, specifically, the well-known suspended particulate matter $\left(\mathrm{PM}_{2.5}\right)$ in the atmosphere. ${ }^{5,6}$ Thus, efficient aerosol retrieval algorithms are required, especially for satellite data on a global scale.

As mentioned previously, this study utilized the features of the GCOM-C/SGLI measurements for aerosol retrieval. However, the SGLI calibrated data will not be released until the end of 2018. Therefore, to fulfill the research requirements, data from the Advanced Earth Observing Satellite (ADEOS)-2 was employed. Launched in December 2002, ADEOS-2 was a short-term Japanese mission within the framework of the International Earth Observation System, and the measurements were provided on a global scale for only 7 months, from April to October in 2003. ADEOS-2 carried the Global Imager (GLI). The GLI was a sensor that preceded GCOM-C/SGLI and had multiobservational channels including the near-UV. The Total Ozone Mapping Spectrometer (TOMS) instrument onboard the Nimbus-7 satellite demonstrated that UV wavelengths were effective for aerosol remote sensing, especially for the absorbing aerosols. ${ }^{7,8}$ Such observations continue via the ozone monitoring instrument (OMI) onboard the Aura satellite. ${ }^{9}$ Herein, the absorbing biomass burning aerosols (BBA) and mineral dust aerosols (called DUST hereafter) were analyzed using the ADEOS-2/GLI near-UV measurements. The ADEOS-2 also carried the Polarization and Directionality of the Earth's Reflectances (POLDER) sensor. POLDER demonstrated the usefulness of polarization data for the analysis of aerosols, ${ }^{10}$ clouds, and aerosols above cloud systems. ${ }^{11}$

The remainder of this paper is organized as follows. In Sec. 2, the detection algorithm for the absorbing aerosols is interpreted. After examination of our algorithm using the GLI data on a global scale, the threshold value facilitating the distinction between the absorbing aerosols and other aerosol types was obtained.

In Sec. 3, the separation algorithm between the two kinds of absorbing aerosols, i.e., BBA and DUST, is discussed and the aerosol classification criteria including clouds are set. Our criteria here prioritize the certainty for each type estimation and the simplicity of the algorithm over encompassing all the data components while retaining ambiguity. As a result, other types of aerosols than BBA and DUST were left out. They are supplemented with the following retrieval work.

In Sec. 4, the aerosol retrieval algorithms based on our radiative transfer (RT) simulations involving the simplified aerosol descriptions are explained. Two types of RT methods were used, namely, the method of successive order of scattering (MSOS) method using ADEOS-2/GLI data for an optically semi-infinite atmosphere model, ${ }^{12}$ and the vector RT (MVRT) method using ADEOS-2/POLDER-2 data for a finite atmosphere. ${ }^{13}$ This section also contains the retrieved aerosol property results derived from the ADEOS-2/GLI and POLDER-2 measurements over case-study targets selected for examining the BBA retrievals.

Finally, a brief summary and the future prospects are presented.

\section{Detection of Absorbing Aerosols}

It has been mentioned above that ultraviolet (UV) data measured by TOMS can detect absorbing aerosols, such as carbonaceous aerosols or mineral dust. ${ }^{7,14}$ The TOMS-AI (aerosol index) is available for the description of absorbing aerosols, and the Aura/OMI inherits the TOMS-AI concept. ${ }^{9,15}$ Further spectral analyses on the complex behavior of organic aerosol refractive 
Mukai, Sano, and Nakata: Algorithms for the classification and characterization of aerosols...

indexes have been conducted. ${ }^{16}$ This is the reason why the near-UV data provided by the ADEOS-2/GLI has been used to detect BBAs from previous studies, where the ratio of reflectance $(R)$ at $0.400 \mu \mathrm{m}$ (band $2 / \mathrm{GLI}$ ) to that at $0.380 \mu \mathrm{m}$ (band $1 / \mathrm{GLI}$ ) was employed to distinguish BBAs from other kinds of aerosols. ${ }^{17}$ Based on this background, we considered the near-UV $(0.380 \mu \mathrm{m})$ and violet $(0.412 \mu \mathrm{m})$ data provided by GCOM-C/SGLI to be useful for detecting absorbing aerosols.

First, we briefly introduce our algorithm ${ }^{18}$ where the ratio of the reflectance at 0.412 to $0.380 \mu \mathrm{m}$ is employed and named as the absorbing aerosol index (AAI):

$$
\mathrm{AAI}=R(0.412) / R(0.380) .
$$

The reflectance $R$ represents the observed satellite value. In this study, the AAI was employed to detect absorbing particles such as carbonaceous aerosols or mineral dust particles (DUST). Note that the definition of our AAI is different from those employed by the TOMS or the Global Ozone Monitoring Experiment ${ }^{19}$ in the formula and the reference channels. They employed a shorter wavelength $(0.340 \mu \mathrm{m})$ than that used in this work, and our index AAI has a simpler form, i.e., only the ratio of the reflectance was applied. As mentioned above, because the polarization sensor SGLI is a successor of the GLI, both sensors have wavelength channels at 0.412 and $0.380 \mu \mathrm{m}$. The AAI, as defined in Eq. (1), can applied to GCOM-C/SGLI and also ADEOS2/GLI data. An examination of the potential for using AAI as an indicator for detecting absorbing aerosols on a global scale during the ADEOS-2 era is a useful case study for SGLI. The SGLI data are now in the trial period and is to be published in December 2018. This work builds upon the benefits of the development of the sensor from GLI to SGLI.

\subsection{Biomass Burning Aerosols}

As a typical example of absorbing aerosols, the BBAs were examined first. BBA plumes are generated by large-scale forest fires or agricultural burns. Though BBA events can occur anytime, typically, large BBA events occur in tropical forests in August and September. BBA events are detected using hot spots derived from the rapid-fire response system (MYD14 Collection 6) of the Terra/MODIS satellite. Figure 1 presents the global distribution of monthly accumulated hot spots (denoted by red dots) from August and September of 2003. These figures clearly depict the occurrence of severe forest fires in southeastern Africa and the Amazon region in August and September, and Indonesia in September.

Based on the results of Fig. 1, we chose data from GLI measurements as BBA case study targets such that almost all selected areas were covered by the BBA event. From the southeastern Africa region (except for the Kalahari Desert), we chose data from August 1 to 2, 4 to 6, 9 to 11, 13 to 14,17 to 22, 24 to 28, and 30, 2003. From the Amazon region (except for the Atacama Desert), we chose data from September 1 to 4,7 to 8,10 to 15 , and 17 to 28, 2003. Lastly, in Indonesia, we chose data from September 1 to 2, 4, 8 to 13,15, 17 to 18, 20, 23, and 27 to 30 ,

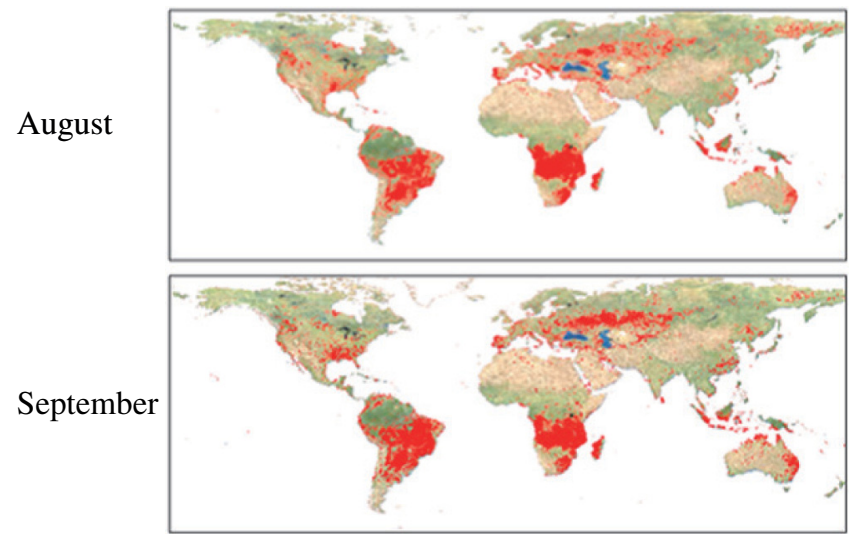

Fig. 1 Global distribution of accumulated monthly hot spots (denoted by red dots) derived from Terra/MODIS (the Rapid-Fire Response System of MYD14 Collection 6) in 2003. 

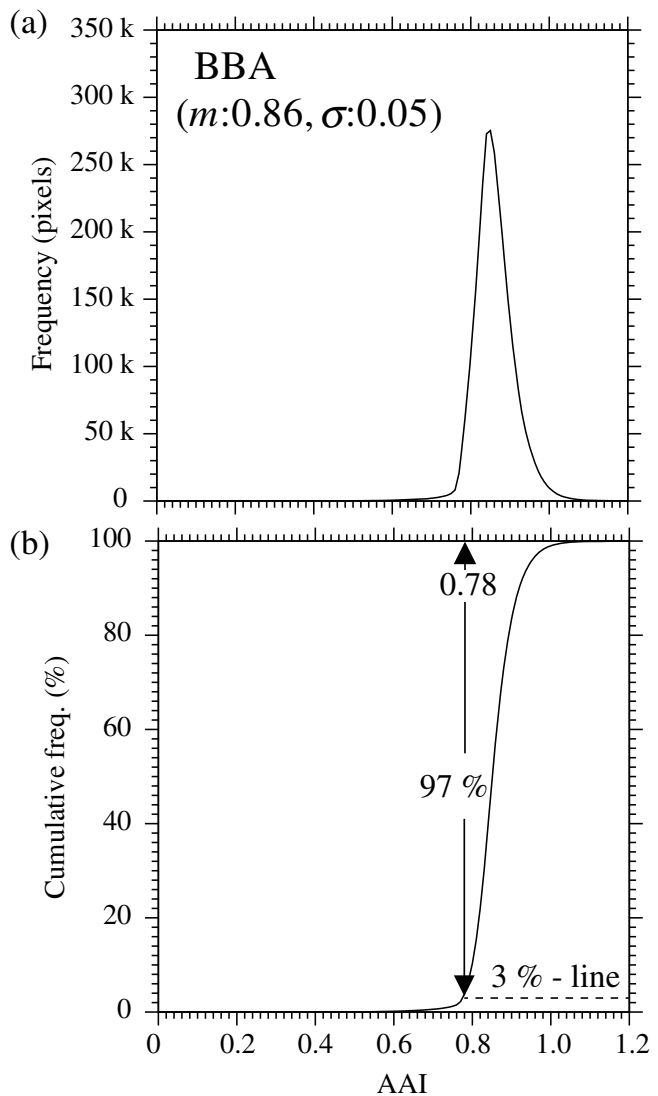

Fig. 2 Histogram of AAl over BBA plume targets in southwestern Africa during August, the Amazon in September, and Indonesia in September of 2003 derived from the GLI measurements. (a) Pixel numbers and (b) the cumulative frequency (\%).

2003. These were regarded as proper candidates for the BBA feasible study. The number of total pixels was $\sim 3,000,000$. Note that the cloud pixels were excluded by the using GLI-cloud flag. Figure 2(a) shows a histogram of the AAIs from the three target regions and Fig. 2(b) provides the cumulative frequency diagram of the upper one. The mean value $(m)$ and the standard deviation $(\sigma)$ of the AAI histogram were 0.86 and 0.05 , respectively. The cumulative frequency diagram [in Fig. 2(b)] showed that the domain of the AAI $\geq 0.78$ (denoted by the dotted line) accounted for $97 \%$ (by the solid arrows) of the total. The results in Fig. 2 indicated that the BBA-AAI values were usually was larger than 0.78 .

In order to compare the data with preceding AAI, Fig. 3 presents a correlation between the GLI-AAI with the TOMS-AI ${ }^{20}$ for the same target areas as those in Fig. 2. Here, the differences in the observing times and effective resolutions between the sensors should be considered. The time difference between the ADEOS-2/GLI and EP/TOMS was restricted within 30 min, and the mean of the GLI-AAI values within a corresponding TOMS-AI pixel was adopted. As a result, the available GLI data were decreased to about 4500, and the correlation coefficient $(\gamma)$ had a value of 0.81. From Fig. 3, it is possible to conclude that the two indices tended to coincide with each other.

Naturally, satellites measure the vertically accumulated radiation, i.e., the satellite data are a mixing of the scattered radiation by atmospheric particles and the reflected radiation from the Earth's surface. The contribution of the bottom surface reflection to the satellite data is considered to decrease with the opacity of the atmosphere, and hence the Earth's surface reflection term becomes offset with the aerosol optical thickness (AOT). Here, we aimed to detect the aerosol characteristics without the interference of the Earth's surface reflection. In the case of an AOT higher than 1.0, there is no significant reason to consider that the bottom surface reflection apparently contributes to the satellite measurements. ${ }^{21}$ Based on this assumption, we assessed the greatest impact of surface reflection on the satellite measurements considering the bottom 
Mukai, Sano, and Nakata: Algorithms for the classification and characterization of aerosols...

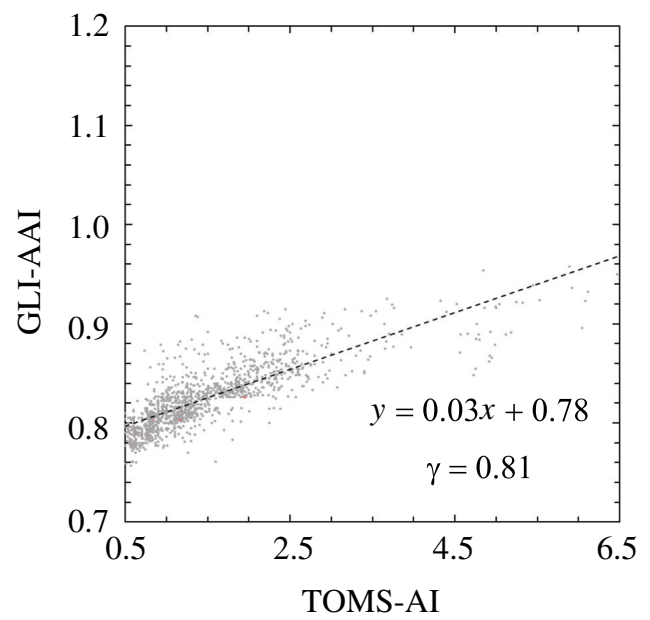

Fig. 3 Comparison of the GLI-AAI with the TOMS-Al over the same targets as in Fig. 2. The TOMS-Al data are from Ref. 20.

surface reflection (surface albedo $=1.0$ ), and the nadir viewing of the satellite at noon. In the case of $\mathrm{AOT}=1$, the satellite can observe about $10 \%$ of the incident solar radiation that is directly reflected by the bottom surface. The satellite observes multiply scattered light due to the occurrence of atmospheric particles and to the interaction of both of scattering and reflection; however, the contribution of reflection to the satellite measurements decreases with AOT. Accordingly, AOT = 1 was selected as suitable value for the measurement of the bottom surface reflection contribution, and the AAI values in the case of an AOT $\geq 1.0$ were investigated here. The relationship between the AAI and the AOT was examined using AOT data derived from Terra/MODIS (MOD04_L2, Coll.6). The time difference between the ADEOS-2/GLI and Terra/MODIS was restricted within $15 \mathrm{~min}$. Figure 4(a) presents the AAI values over the BBA-dominant areas versus MODIS/AOT $(0.550 \mu \mathrm{m})$. The red dots represent the averaged AAI values at each AOT. It was found that the AAI values increased with the AOT and the AAI values converged around the average values beyond the AOTs $(0.550 \mu \mathrm{m})=1.0$. The case of an AOT $(0.550 \mu \mathrm{m}) \geq 1.0$ seemed to suggest that aerosols are optically thick enough for aerosol scattering itself to contribute to the satellite measurements with less interference from of the Earth's surface reflection. Namely, the AAI values in the case of an AOT $\geq 1.0$ just provided by BBAs had AAI values of $\geq 0.83$. In order to confirm this finding, Fig. 4(b) presented the histogram and cumulative frequency $(\%)$ of the AAI for the BBA. Namely, the GLI data used as the BBA in Fig. 4(b) were restricted within the right upper domain (consisting of about 9000 pixels) in Fig. 4(a). Figure 4(b) shows that almost all of the BBAs (99\%) acquired the AAI values greater than 0.83 .

\subsection{Mineral Dust Aerosols (DUST)}

Here, the mineral dust particles (DUST) were examined as another typical type of absorbing aerosol. $^{7,22}$ It is natural to consider that the main generation sources of mineral dust are deserts, and hence the desert areas given by the International Geosphere-Biosphere Programme (IGBP) were selected for the dust aerosol trial targets. Figure 5 is similar to Fig. 2, except for the intrinsic DUST, i.e., the selected mineral dust aerosols over the desert with an AOT $(0.550 \mu \mathrm{m}) \geq 1.0$. The AOT values were obtained from the Terra/MODIS deep blue algorithm (MOD04_L2, Collection $6)$. The time difference between the ADEOS-2/GLI and Terra/MODIS was restricted within 15 min. The solid lines in Fig. 5 approximately represent the AAI values for the DUST. In other words, the solid lines in Fig. 5 correspond to Fig. 4(b) rather than Fig. 2. Figure 5(a) presents the histograms of the summarized AAI values recorded over the deserts from May to September, 2003. For reference, the AAI values over the optically thin (AOT < 1.0) desert areas are shown by the dotted line in the upper histogram. The corresponding GLI pixels were about 8,400,000 in total, and the DUST cases were about one-eighth of the total. It was evident that the DUST had 
(a) BBA - AAI versus AOT

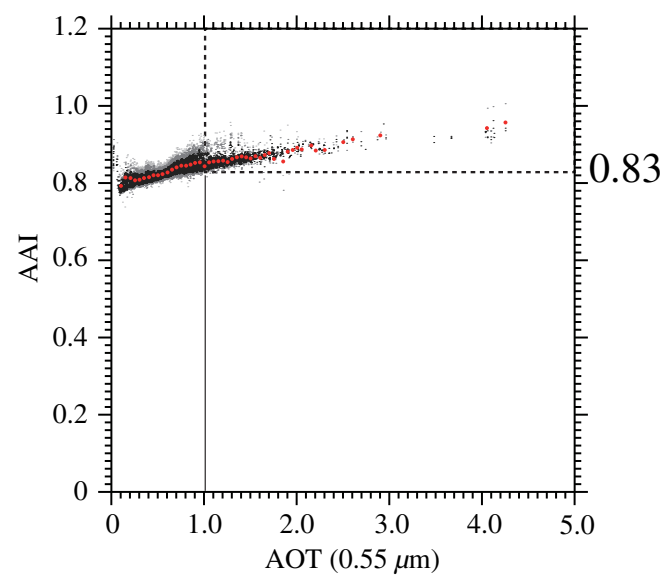

(b) BBA - AAI

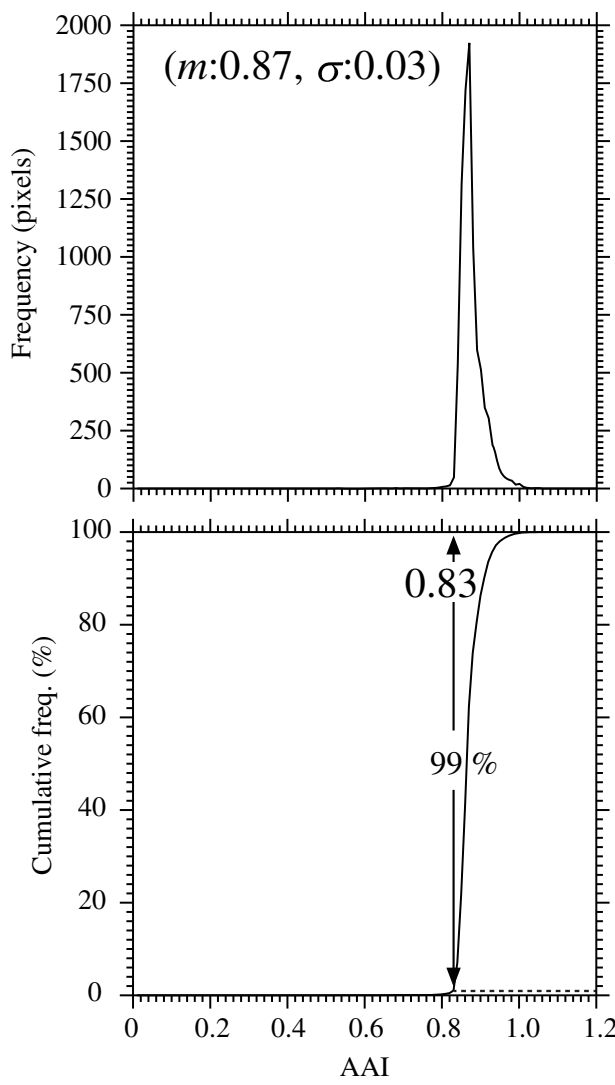

Fig. 4 (a) Verification of the BBA-AAI dependency on the AOT $(0.550 \mu \mathrm{m})$. The AOT values were obtained from Terra/MODIS (MODIS/MOD04_L2 Collection 6). And (b) presents the AAI histogram of the genuine BBA. (a) The pixel numbers and (b) cumulative frequency (\%).

higher AAI values than those of the BBA. Almost all of the DUST (97\%) (denoted by the solid arrows) acquired the AAI $\geq 0.9$ value (the dotted line); however, BBAs also were found in this domain with an AAI $\geq 0.9$ (refer to Figs. 2 and 4). This fact suggests that a different index other than the AAI must be determined to effectively distinguish the BBAs from the DUST.

The AAI as a reflectance ratio of $R(0.412 \mu \mathrm{m}) / R(0.380 \mu \mathrm{m})$ was interpreted in this study for the detection of absorbing particles. Our AAI index was the ratio of the satellite measurements of two-channels in the near-UV that will be available soon for the JAXA/GCOM-C/SGLI satellites. Select data observed by ADEOS-2/GLI in 2003 were used in this study. Although obtaining accurate AAI values requires more precise treatments with the SGLI, the resultant threshold AAI value obtained in this study was AAI $\geq 0.83$ to distinguish absorbing aerosols such as BBA and DUST from other types of aerosols. In addition, DUST may have higher AAI $(\geq 0.90)$ values than BBAs as mentioned above, namely AAI-DUST $>$ AAI-BBA. To the extent that has been discussed up to this point, Fig. 6 is an approximate AAI classification with respect to the continental aerosols, such as DUST, BBA, and other types of aerosols (others). The BBA denotes BBA for an AOT $\geq 1.0$ as already mentioned in Fig. 4. The domain AAI $\geq 0.9$ in Fig. 6 requires the separation of the BBA from the DUST by a method other than the AAI.

\section{DUST Detection}

\subsection{Discrimination of BBA from DUST}

As mentioned in the previous section, only the AAI was unable to distinguish BBAs from DUST in the AAI domain greater than 0.9. Referring to the dust detection algorithm for MODIS 
Mukai, Sano, and Nakata: Algorithms for the classification and characterization of aerosols...

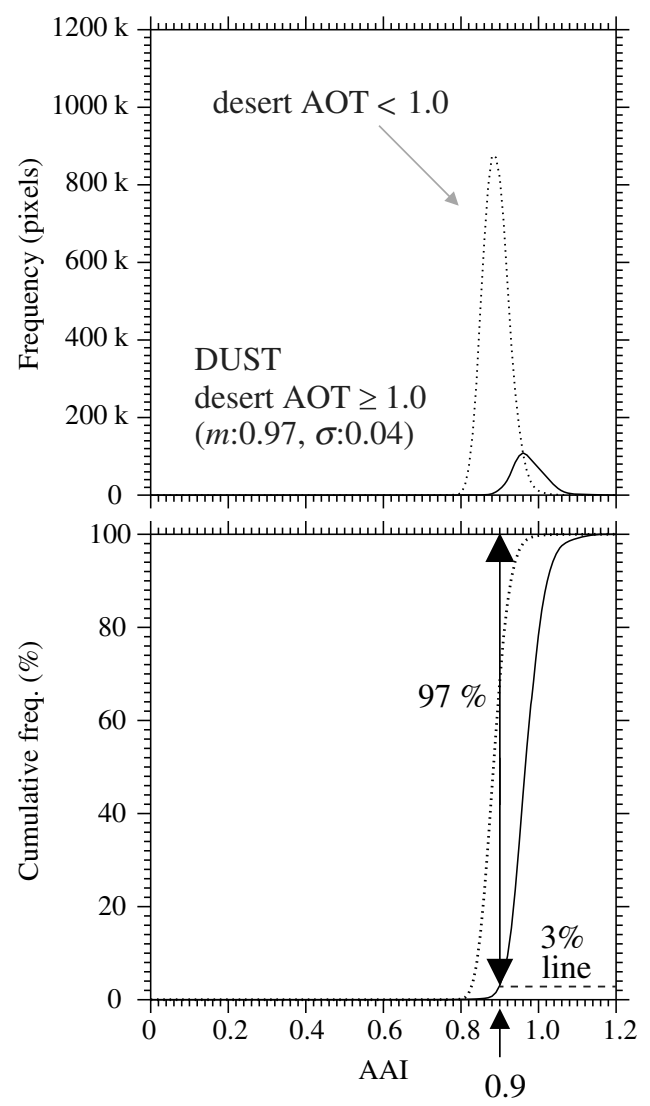

Fig. 5 AAI Histogram of DUST over the desert areas referred from the IGBP from May to September 2003 derived from the GLI measurements. The data were selected for AOTs $(0.550 \mu \mathrm{m}) \geq 1.0$. The AOT values were obtained from the Terra/MODIS deep blue algorithms (MODIS/MOD04_L2 Collection 6). (a) The pixel numbers and (b) cumulative frequency (\%).

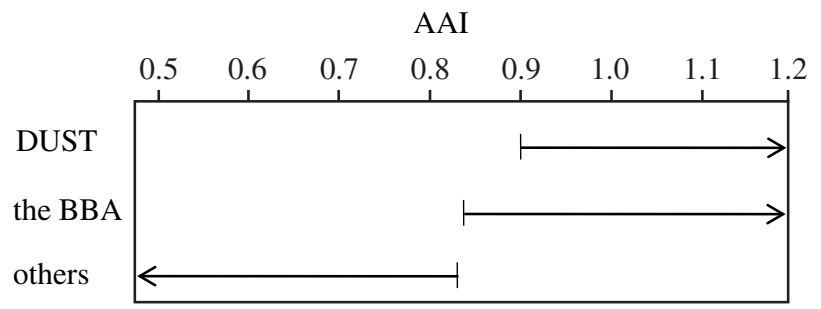

Fig. 6 Classification of continental aerosols in terms of the AAI numerical values (AAI, aerosol absorption index).

measurements proposed by Ciren and Kondragunta, ${ }^{23}$ the $2.210-\mu \mathrm{m}$ band was adopted to detect DUST in this study. The availability of the shortwave infrared wavelengths for the detection of dust aerosols has already been established. ${ }^{24}$ Then, in a similar manner to Eq. (1), a reflectance ratio $(R)$ at a wavelength of $2.210 \mu \mathrm{m}$ to that of $0.380 \mu \mathrm{m}$ was defined as the DDI:

$$
\mathrm{DDI}=R(2.210) / R(0.380) \text {. }
$$

Figure 7 presents the DDI histogram for the same DUST data as in Fig. 5, namely with the selected mineral dust aerosol data for AOTs $(0.550 \mu \mathrm{m}) \geq 1.0$. Figures 7 (a) and 7 (b) show the DDI histograms and the cumulative frequency, respectively, for the summarized data from May to September, 2003. It was found from Fig. 7 that almost all of the DUST (99\% denoted by the solid arrows) acquired DDI values $\geq 0.73$. Simply speaking, the values of DUST-DDI were greater than 0.73 . 


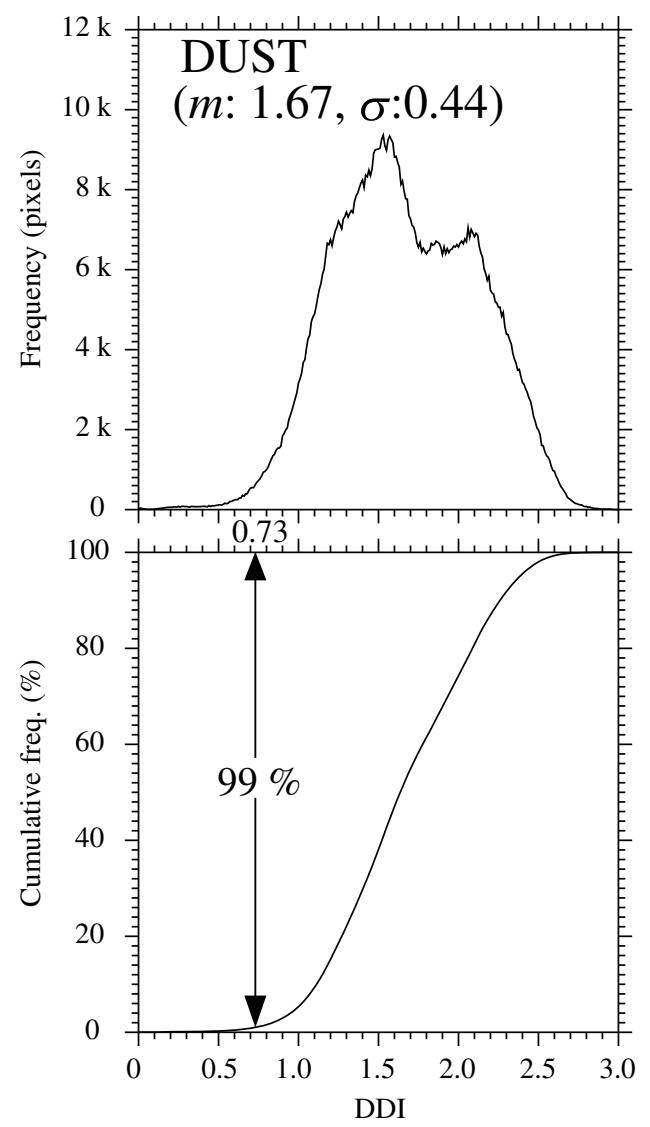

Fig. 7 (a) The histogram and (b) cumulative frequency graphs of the DDI for DUST. The data are the same as the solid line in Fig. 5.

Next, the DDI for the BBAs was considered. Figure 8 shows the BBA-DDI, where the GLI data were the same as that adopted in Fig. 4. Figure 8(a) is the same as Fig. 4(a), except for the DDI. The BBA-DDI values acquired $\sim 0.7$ at low AOTs and rapidly decreased with the AOT until $\mathrm{AOT}=1$, and then the DDI values slowly changed beyond AOT $=1$. At that point, it became possible to say that the BBA acquired lower DDI values than $\sim 0.7$. Figure $8(\mathrm{~b})$ is the same as Fig. 4(b), except for the DDI. Namely, Fig. 8(b) was used to determine the precise DDI values for the BBA. Comparing Figs. 7 and 8 provided us with the conclusion that DDI $=0.73$ was the threshold value to distinguish between the BBAs and DUST.

It was concluded from the above discussions that the combined use of the AAI and DDI indices enables us to separate absorbing aerosols into BBAs and DUST. In other words, the classification criteria for the aerosol types were obtained. ${ }^{25}$

\subsection{Cloud Detection}

Here, the difficult issue pertaining to detecting clouds in terms of our AAI and DDI was challenged in addition to discriminating the aerosol type. A comparison between both AAI histograms on a global scale with and without clouds suggested that clouds led to low AAI values in the previous study. ${ }^{18}$ To be more precise, the cloud AAI values must be less than those of the aerosols. If this is corroborated, clouds could simply detected be using the AAI; however, it appears that this may be more complicated in practice. The cloud AAI values depend on the season, location, height, type, and relative position of the sun. It should be noted more above all that satellite measures accumulate signals from space, and hence a variety of information is incorporated in the satellite data, especially the cloud heights.

First, the AAI and DDI values were examined for cloud flag pixels. Figure 9 shows two kinds of indices for the AAI and DDI in Figs. 9(a) and 9(b), respectively. In Fig. 9, the cloud flag and 
Mukai, Sano, and Nakata: Algorithms for the classification and characterization of aerosols...

(a) BBA - DDI versus AOT

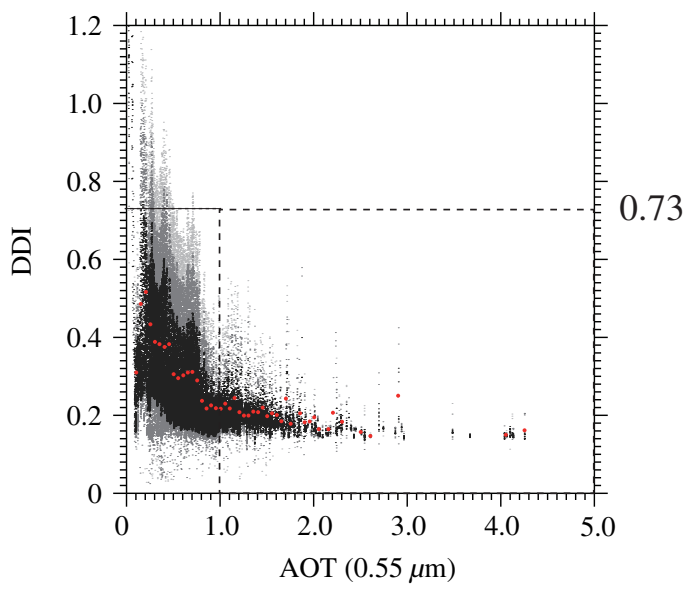

(b) BBA - DDI
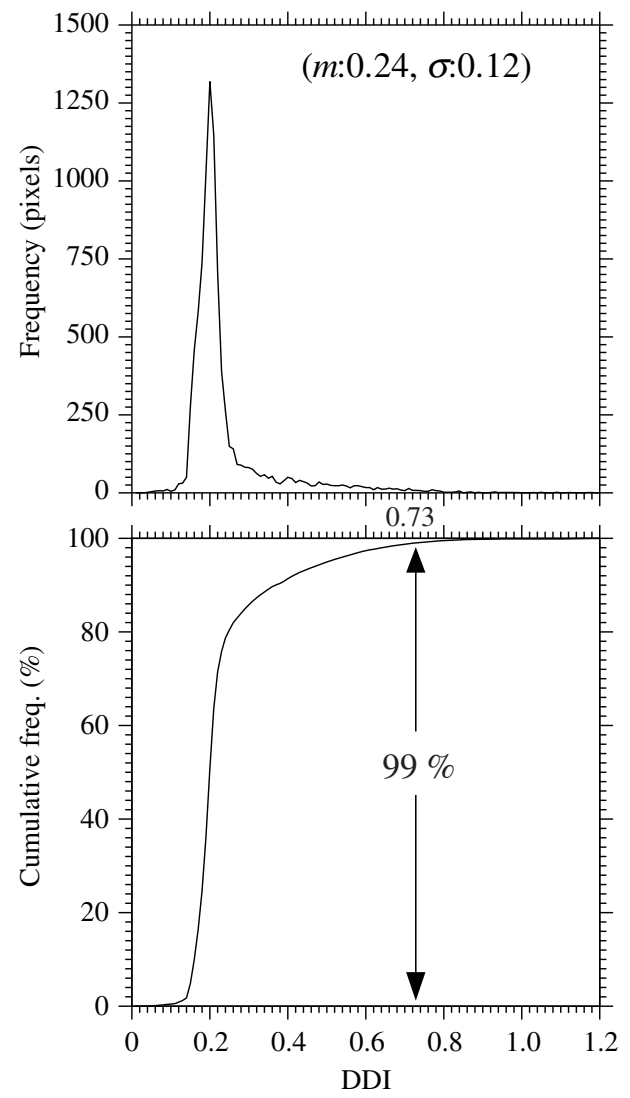

Fig. 8 Detection of the BBA-DDI. (a) BBA-AAI dependency on the AOT based on the same GLI data as that in Fig. 4. (b) Histogram of the DDI for the BBA within the right square domain surrounded by the thick dashed line in (a).

cloud optical thickness [COT $(0.670 \mu \mathrm{m})$ ] were derived from the ADEOS-2/POLDER measurements. The COT behavior of the ice clouds seemed to differ from the water ones, and the AAI and DDI values for the ice clouds converged faster with the COT than with the water clouds. This feature was clearly found in the histogram of Fig. 9(b), where the first and the second peaks corresponded to the ice and the water clouds, respectively. Also, mixed regions of clouds and aerosols are frequently found. In order to further explore issue, more precise handling of the clouds is needed. Focusing on the aerosol retrievals, the task was concentrated to detect regions clearly not attributed to aerosols. The structure and physics of clouds are complex; hence it is impossible to detect clouds, especially optically thin cirrus clouds, using only these two indices. If we ignored such a fine feature, both clouds indices showed stable behavior in the region with a $\operatorname{COT}(0.670 \mu \mathrm{m}) \geq 20$. The clouds with COT $(0.670 \mu \mathrm{m}) \geq 20$ in Fig. 9 required $\sim 1,500,000$ pixels corresponding to $21 \%$ of the total clouds. Figure 9 suggested clouds thick enough to cover the underlying aerosols or the Earth's surface, and the AAI and DDI acquired values less than equal to 0.65 and 0.6 , respectively. In other words, the thick clouds with optical thickness COT $(0.670 \mu \mathrm{m}) \geq 20$ were detected with AAI values $\leq 0.65$ and DDI values $\leq 0.6$. It could be say from Fig. 9 that these threshold values of AAI and DDI covered the rather thin clouds having $5 \leq$ COT $(0.670 \mu \mathrm{m}) \leq 20$.

\subsection{Aerosol Classification Criteria}

An aerosol type and cloud discrimination chart created by merging Figs. 6-9 in the two-dimensional coordinates of the AAI and DDI is shown in Fig. 10. The yellow, red, black, and light gray colors represent DUST, BBA, clouds, and other types, respectively. Note that "clouds" indicates 
Mukai, Sano, and Nakata: Algorithms for the classification and characterization of aerosols...

(a) Cloud - AAI
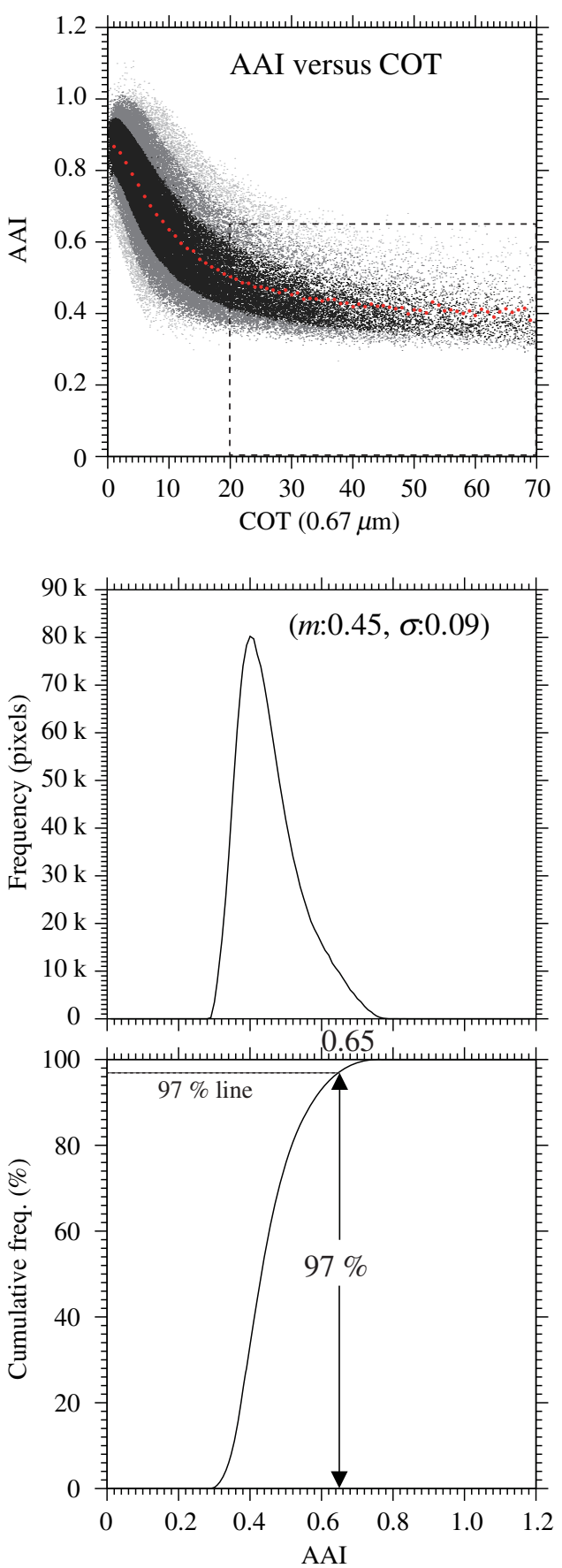

(b) Cloud - DDI
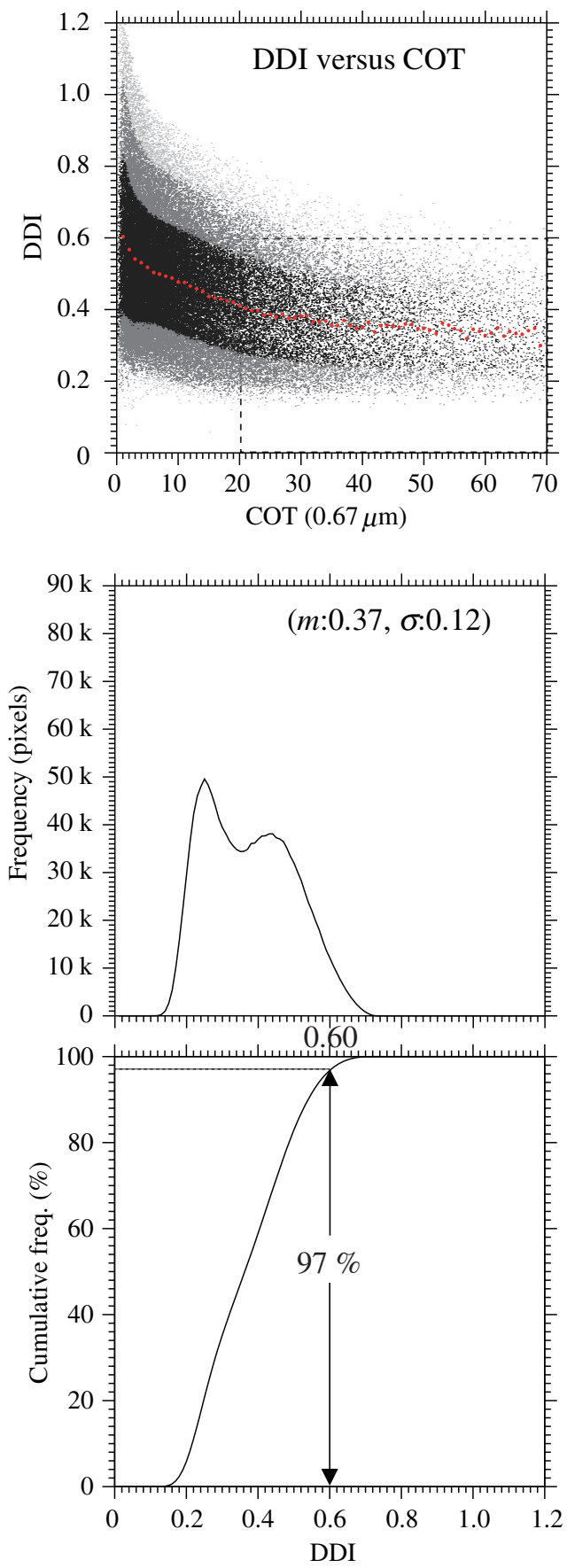

Fig. 9 (a) Cloud detection by AAI and (b) DDI from the GLI data in 2003. The top is the AAI and DDI versus COT from the ADEOS-2/POLDER-2 data, and the bottom is the histogram and cumulative frequency (\%) for COT $\geq 20$.

those thick enough to cover the underlying aerosols or the surface, BBA represents the "genuine BBA" shown in Fig. 4, and "others" include the nonabsorbing aerosols, a mix of several types of aerosols, unknown aerosols, or unclear regions. These ambiguities were resolved to some extent in the following aerosol retrieval process.

As an example, Figs. 11(a)-11(c) show the true color composite image, consisting of colorspace GLI data (R:0.678, G:0.545, B:0.443 $\mu \mathrm{m}$ ), the classified aerosol types on a global scale according to the criteria shown in Fig. 10 and the GLI-cloud flag for clouds, respectively, on 
Mukai, Sano, and Nakata: Algorithms for the classification and characterization of aerosols...

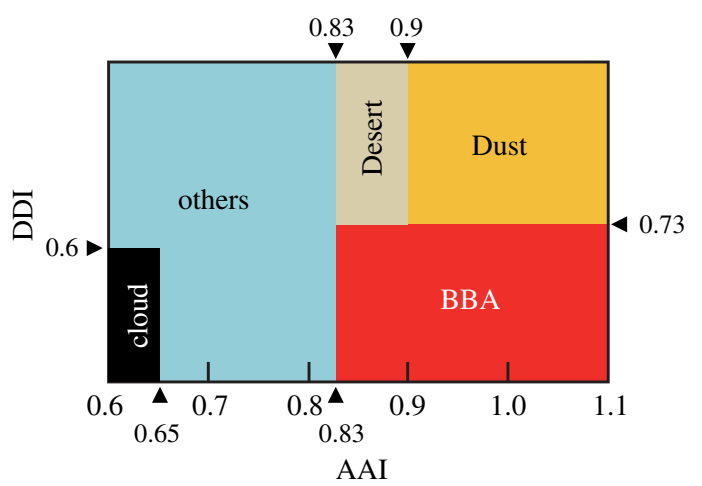

\begin{tabular}{|c|c|c|}
\hline type & AAI & DDI \\
\hline Dust & $\geq 0.9$ & $\geq 0.73$ \\
\hline Desert & $\geq 0.83$ & $\geq 0.73$ \\
\hline BBA & $\geq 0.83$ & $<0.73$ \\
\hline cloud & $<0.65$ & $<0.6$ \\
\hline others & & \\
\hline
\end{tabular}

Fig. 10 An aerosol type discrimination chart in two-dimensional space. The horizontal and vertical axes denote the AAI and DDI values, respectively.

(a)

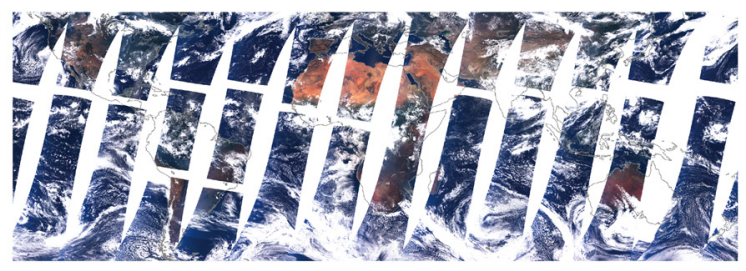

(b)

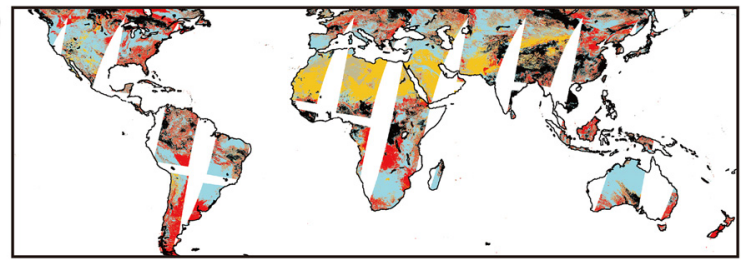

\begin{tabular}{|c|r|}
\hline others & $44 \%$ \\
\hline Cloud & $26 \%$ \\
\hline BBA & $14 \%$ \\
\hline Dust & $13 \%$ \\
\hline Desert & $3 \%$ \\
\hline
\end{tabular}

(c)

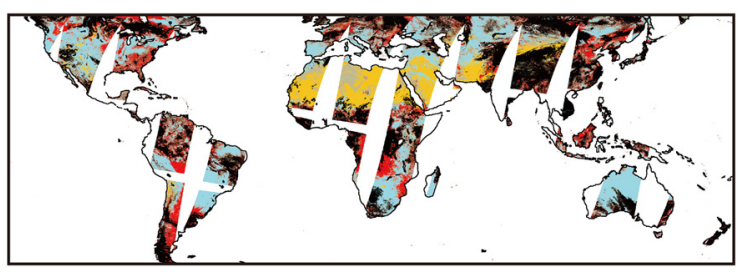

\begin{tabular}{|c|r|}
\hline others & $34 \%$ \\
\hline Cloud & $33 \%$ \\
\hline BBA & $19 \%$ \\
\hline Dust & $11 \%$ \\
\hline Desert & $3 \%$ \\
\hline
\end{tabular}

Fig. 11 (a) The true color composite image consisting of data on August 20, 2003. Aerosol types were classified from the GLI data, observed on the same day and derived based on the criteria shown in Fig. 10, and those using the GLI-cloud flag to cloud data only, in (b) and (c), respectively.

August 20, 2003, from the ADEOS-2/GLI measurements. Because the discrimination chart in Fig. 10 was the first and fast guide-posting to the precise aerosol characteristics, further retrieval processing was absolutely necessary. However, in Fig. 11(b), the BBA regions seemed to be overestimated although August was the season for the biomass burning (BB) episodes. One of the reasons might be caused by the cloud detection criterion. The AAI and DDI threshold values for cloud classes were restricted in the case of optically thick clouds with COT $\geq 20$ in Fig. 10 as previously mentioned. As a result, thin clouds might be misinterpreted as BBAs or other types. This fact was suggested from the color composite image in Fig. 11(a). To confirm, Fig. 11(c) presented the global classification of aerosols according to the criteria in Fig. 10 with the exception of cloud classes determined by the GLI cloud flag. Comparing Figs. 11(c) to Fig. 11(b), the cloud portions increased and the BBA- and others-regions decreased. As such, the cloud regions in Fig. 11(b) were completely included in those in Fig. 11(c) and the former occupied $42 \%$ of the latter. It was found that with the cloud detection criterion proposed in Fig. 10 it was possible to catch nearly half of the clouds. From the standpoint of aerosol retrieval, it was efficient to ensure that nearly half of the cloud region could be pre-excluded. Through this process, the difficulty of cloud detection and the necessity of the following aerosol characterization were revealed. 


\section{Characterization of Aerosols}

\subsection{Aerosol Model}

The characteristics of aerosols can be represented using several parameters. The most basic parameter is the spectral $\operatorname{AOT}(\lambda)$ at wavelength $\lambda .^{26}$ The Ångström exponent (AE) is derived from the spectral $\operatorname{AOT}(\lambda)$ and is closely related to the aerosol size. ${ }^{27}$ In general, the AE values from $\sim 0$ to 1.0 indicate large particles (e.g., sea-salt aerosols and soil dusts), whereas values in the range $1.0<\mathrm{AE}<2.5$ indicate particles such as sulfates and those associated with $\mathrm{BB} .{ }^{28}$ The detection of high AE values almost always indicates contamination by small anthropogenic particles. Several other aerosol parameters, such as the size distribution and refractive index, are also derived from the $\operatorname{AOT}(\lambda)$ and sky radiances. ${ }^{29,30}$ According to the automatic classification of accumulated NASA/AERONET data, atmospheric aerosols are classified into the following six categories: (1) $\mathrm{BB}$, an aged smoke aerosol consisting primarily of soot and organic carbon; (2) rural (RU), referred to as a clean continental aerosol; (3) continental pollution (CP), representing anthropogenic aerosols, including various species of sulfate- $\left(\mathrm{SO}_{4}^{2-}\right)$, nitrate- $\left(\mathrm{NO}_{3}^{-}\right), \mathrm{OC}$, ammonium $\left(\mathrm{NH}_{4}^{+}\right)$, and soot; (4) dirty pollution, consisting of the same aerosol types as $\mathrm{CP}$, but at significantly higher levels; (5) desert dust, assumed to be mostly mineral soil; and (6) polluted marine, consisting primarily of sea salt with traces of $\mathrm{CP}^{31}$

First, we investigated the aerosol sizes. The size distributions of these six aerosol types had two modes (fine and coarse) in a bimodal log-normal distribution of the particle volume with six parameters (volume concentration, mode radius, and the standard deviation of the fine and coarse mode particles). Too many parameters are excessive for the retrieval of the optimized aerosol sizes at a global scale. Therefore, a simplification was made for the aerosol size distribution function. ${ }^{21}$ As a result, the size distribution function for continental aerosols $(V)$ can be approximately expressed in a simpler form, defined by the unique variable of the fine particle fraction $(f)$ of the volume concentration ${ }^{32}$ :

$$
\frac{d V}{d \ln r} \sim \frac{f}{\sqrt{2 \pi} \ln 1.533} \exp \left[-\frac{(\ln r-\ln 0.144)^{2}}{2 \ln ^{2} 1.533}\right]+\frac{(1-f)}{\sqrt{2 \pi} \ln 2.104} \exp \left[-\frac{(\ln r-\ln 3.607)^{2}}{2 \ln ^{2} 2.104}\right] .
$$

The next aerosol characteristic of interest is the refractive index. It is reasonable to consider that a mixture of various aerosol types exists in nature. Therefore, many studies have been conducted with respect to the mixing of various particle types. ${ }^{33-36}$ Although particle mixing is an issue to be considered as well as understood, a simple homogeneous internal two-component mixing model was adopted here, using the Maxwell Garnett mixing (MGM) rule. ${ }^{37}$ The MGM rule provides a complex refractive index calculated as follows:

$$
\varepsilon=\varepsilon_{m} \frac{\left(\varepsilon_{j}+2 \varepsilon_{m}\right)+2 g\left(\varepsilon_{j}-\varepsilon_{m}\right)}{\left(\varepsilon_{j}+2 \varepsilon_{m}\right)-g\left(\varepsilon_{j}-\varepsilon_{m}\right)},
$$

where $\varepsilon$ denotes the dielectric constant, the subscripts $m$ and $j$ represent the matrix and inclusion, respectively, and $g$ is the volume fraction of the inclusions. The present aerosol retrieval was made using visible and near-IR band data because the refractive index can be assumed as independent of the wavelength in these spectral regions. It was determined that the matrix and inclusions were $1.410-0.004 i$ and $1.520-0.035 i$, respectively, for applications using the visible band data. This indicated that the matrix and inclusions are weakly and strongly absorbing particles, respectively. Moreover, the spectral absorption (i.e., the imaginary part of the refractive index) was considered at near-UV wavelengths. ${ }^{16,38,39}$ In short, the aerosol models can be more simply represented by two parameters $(f, g){ }^{32}$ the size of the aerosols can be represented by an approximate bimodal log-normal distribution defined by the fine particle fraction $(f)$, as given by Eq. (3), and the refractive index can be deduced from the internal mixing of aerosol types with the volume fraction of the inclusions $(g)$, by Eq. (4). In spite of this simplified description of aerosol models, many aerosol models must be used, especially for global-scale data processing.

Figure 12 presents the block flow of our aerosol retrieval method from the satellite data. Part "C" represents the debated section of the aerosol type classifications based on the near-UV 


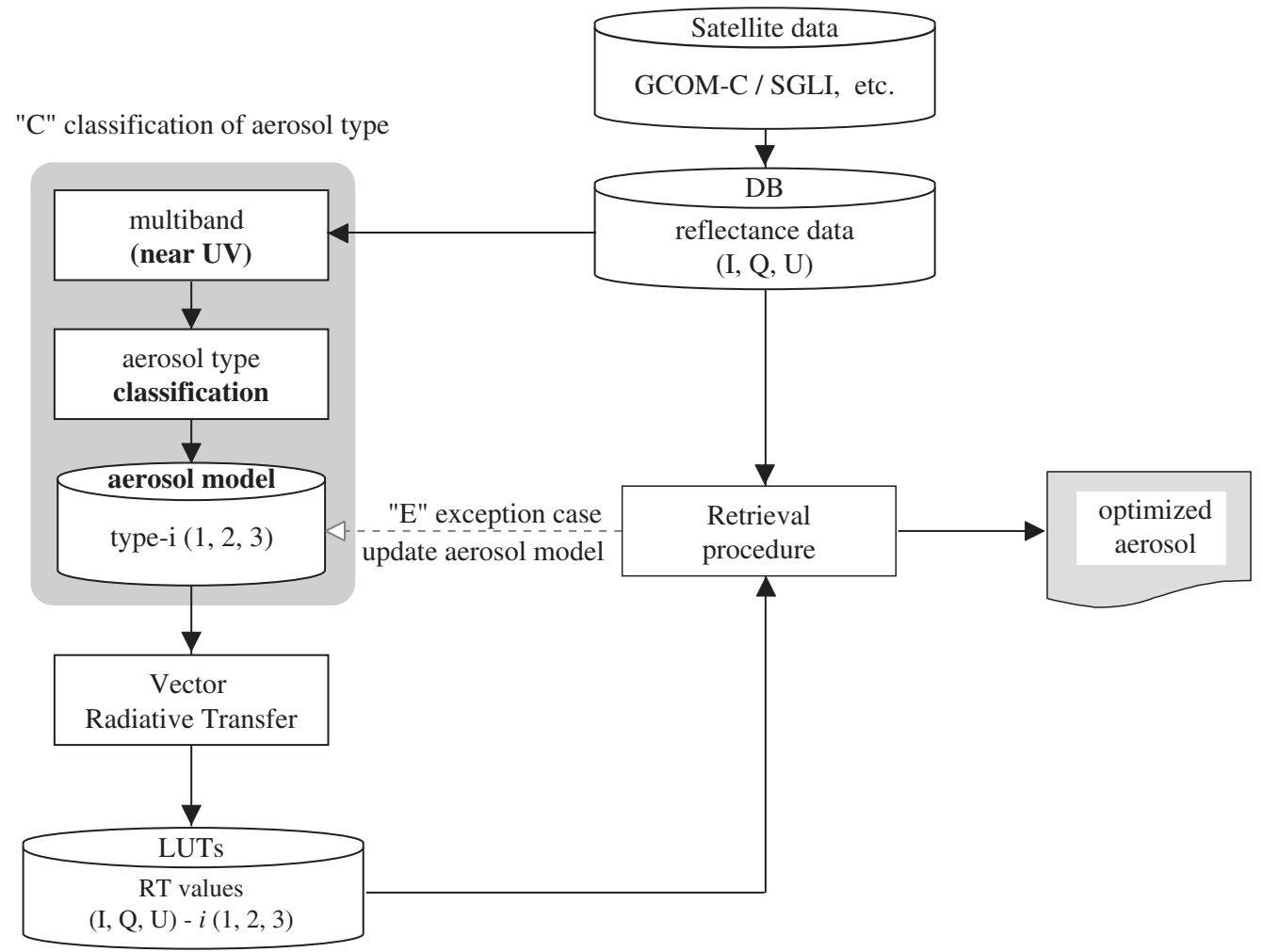

Fig. 12 Block flow diagram for the satellite data aerosol retrievals. Section "C" represents the debated section of the aerosol type classification based on the near-UV measurements, and " $E$ " is an exceptional nonconforming case for the prepared aerosol models.

measurements mentioned in the previous section. The key point of this study is that the advance classification of aerosol types using near-UV data is efficient for aerosol retrievals. This is important because radiation simulations require long computing times for the various aerosol models at each satellite data pixel. Best of all, useful information can be obtained beforehand about aerosol types using just the simple AAI and DDI color ratios that provide a rough overview of the aerosol characteristic distribution and can immediately be applied on a global scale. It is reasonable to consider that aerosols are naturally mixed and heterogeneous, and hence part of "E" in Fig. 12 corresponds to an exception-handling procedure for cases that do not conform to the prepared aerosol types. This exception handling can be compensated for by using interpolations between some of the prepared aerosol types; however, further work is needed in order account for these exceptional cases to increase the accuracy of the retrieved aerosol properties.

\subsection{Retrieval of Aerosol Properties in Heavy BBA Events}

During aerosol episodes, extremely dense aerosol concentrations can occur. In other words, very high AOT is assumed during heavy aerosol episodes because the AOT is proportional to the amount of aerosols in the atmosphere. The basic framework for aerosol retrievals from satellite data is roughly divided into two parts: satellite data processing and radiation simulation calculations in atmosphere of the Earth involving aerosols and molecules. It is reasonable to consider that AOT values are very high during aerosol episodes where the incident solar radiation induces multiple interactions with atmospheric aerosols due to the dense radiation field. Unfortunately, precise simulation of multiple light-scattering processes requires very large computation times. The RT simulations for such cases have been treated with a process called the MSOS. ${ }^{12,40}$ The MSOS effectively calculates the upward intensity of radiation at the TOA (i.e., the reflectance of the optically semi-infinite atmosphere model as AOT $\approx \infty$ ). Consequently, the ground-surface reflection property can be ignored because the optical thickness of the atmosphere is too high to be affected by the radiation interaction of the atmosphere with the ground surface. In practice, 
ADEOS-2/GLI measurements over the area around the border of Mozambique and South Africa on August 20, 2003, where typical BBA episodes were occurring, were selected to satisfy the MSOS conditions mentioned above. The target acquired values of AAI $=0.95$ and DDI $=0.20$. It was observed from Figs. 4(a) and 8(a) that the values of both indices satisfied the high AOT conditions. This fact suggested that the MSOS was applicable for radiation simulation in this target.

The aerosol retrieval targets were preferably selected around AERONET sites for later validations. As noted above, the BBA model is described by only the $f$ and $g$ parameters. We compared the GLI measurements (represented by dots) with the simulated reflected intensity values calculated by the radiation simulations in a two-channel diagram with wavelengths of 0.443 and $0.545 \mu \mathrm{m}$ in Fig. 13. Therefore, the two $f$ and $g$ parameters, i.e., the aerosol size distribution and refractive index, respectively, were used for the radiation simulations based on the MSOS. Accordingly, the optimized values $(f *, g *)$ were estimated from the two wavelength planes. Once the $g$ value had been determined, the refractive index was calculated using the MGM rule [see Eq. (4)]. A detailed description of this procedure was presented in previous studies. ${ }^{6,21}$ The dots in Fig. 13 denote the ADEOS-2/GLI data over the target on August 20, 2003. Furthermore, the desired aerosol property of the imaginary part of the complex refractive index at $0.38 \mu \mathrm{m}$ was derived from the comparison of the reflectance value by the RT simulations with the GLI/Band-1 $(0.380 \mu \mathrm{m})$ measurements. The parameters and retrieved results of the aerosol characteristics are summarized in Table 1 . The retrieved parameters values $(f *)$ indicated small particle sizes. The obtained refractive index suggested the particles were weakly absorbing aerosols. Note that the imaginary part of the refractive index in the near-UV was rather large. In other words, the BBA absorption in the near-UV due to forest fires was observed.

The retrieved aerosol properties presented in Fig. 13 and Table 1 should be compared with the ground measurements for validation. However, the simulations were unfortunately limited to the

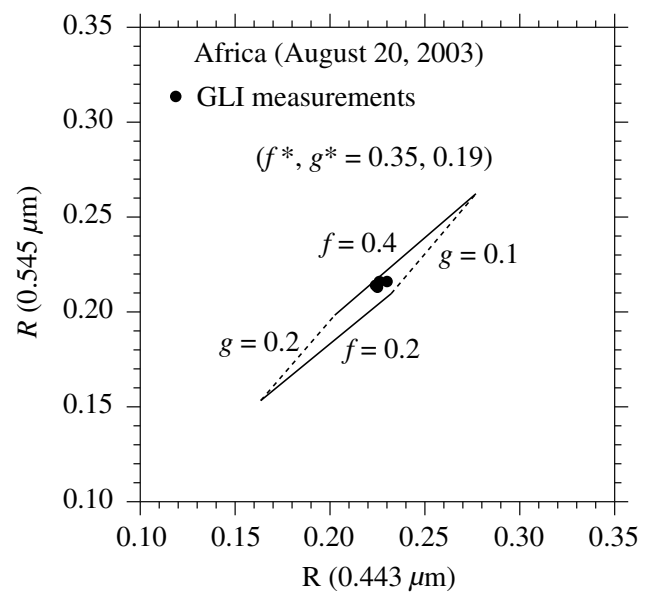

Fig. 13 Calculated reflectance values based on the MSOS RT algorithm for our proposed aerosol models, described by two parameters $(f, g)$ in a two-channel 0.443 and $0.545 \mu \mathrm{m}$ diagram. The solid and dashed curves denote the results for various values of $f$ and $g$, respectively. The dots denote the ADEOS-2/GLI data for the case study target. The values $(f *, g *)$ denote the retrieved values optimized for the GLI measurements.

Table 1 Retrieved aerosol characteristics based on the MSOS using the ADEOS-2/GLI measurements at $0.545,0.443$, and $0.380 \mu \mathrm{m}$.

\begin{tabular}{lccc}
\hline \hline $\begin{array}{l}\text { Target area } \\
\text { Place and date (2003) }\end{array}$ & $\begin{array}{c}\text { Fine particle relative } \\
\text { concentration: } f^{*}\end{array}$ & $\begin{array}{c}\text { Refractive index } \\
(0.545 \text { and } 0.443 \mu \mathrm{m})\end{array}$ & $\begin{array}{c}\text { Refractive index } \\
(0.380 \mu \mathrm{m})\end{array}$ \\
\hline $\begin{array}{l}\text { S-Africa, } \\
\text { August 20 }\end{array}$ & 0.35 & $1.44-0.010 i$ & $1.44-0.012 i$ \\
\hline \hline
\end{tabular}


severely hazy case, and therefore the ground measurements were not available. Then, reproduction calculations of the MSOS using the retrieved aerosol parameters presented in Table 1 were performed and compared with the original satellite data for validation of the present retrieval. The maximum error fell within 3\%. The MSOS method has been applied to other aerosol events in previous works, such as a forest fire in the Amazon ${ }^{12}$ and a severe air pollution case in eastcentral China. ${ }^{21}$ In these studies, the difference between the resimulation results and the MODIS measurements was within $3 \%$. The validation of the retrieved aerosol properties around the target was examined together with the finite atmosphere treatments and discussed in the next section.

\subsection{Aerosol Retrieval with ADEOS-2/POLDER-2}

Satellite remote sensing usually provides the spatial distribution of aerosol properties. Nevertheless, in the previous section, the aerosol retrievals were limited to point analyses due to the heavy aerosol concentration restrictions. In this section, the retrieval target was expanded in the vicinity of the target point. In addition to the results obtained in the previous section, we estimated two more aerosol properties, i.e., optical thickness (AOT) and AE, based on the polarization measurements at 0.670 and $0.865 \mu \mathrm{m}$ observed by the POLDER-2 sensor on ADEOS-2. It has been accepted that polarization information is very effective for aerosol retrievals over land. The retrieval algorithm was similar to previous studies, ${ }^{41}$ and is referred to as the method of vector radiative transfer (MVRT) for convenience, and the polarized reflectance by the bottom surface was interpreted by the model proposed by Bréon et al. ${ }^{42}$ It was found that the refractive index values were the same in the visible wavelength except for the near-UV, but that the size of the aerosols differed from each other. The refractive index was fixed at 1.44-0.010i around the target (Table 1). Accordingly, two aerosol parameters (AOT, $f$ ) were retrieved in a two-channel polarized radiance of 0.670 and $0.865 \mu \mathrm{m}$ provided by the ADEOS-2/POLDER-2.

Our algorithm was applied to the BB scene in the vicinity of the same point and time treated in the previous section. Figure 14 presents a composite image captured by Terra/MODIS on August 20, 2003, over southern Africa. It can be seen at a glance that the diagonal right half of the image is covered by smoke.

The high AOT regions were widely distributed around the central region in Fig. 15(a). The $\mathrm{AE}$ value that was calculated from the AOT and $f$ around this high AOT region was greater than 2 [Fig. 15(b)]. This implied that the small particles were in the atmosphere. For validation of the retrieval results, the Terra/MODIS products (MOD04_L2 Collection 6.1) were inferred [see Figs. 15(c) (AOT at $0.5 \mu \mathrm{m}$ and 15(d) (AE)]. The correlations between the AOT $(0.5 \mu \mathrm{m})$ retrieved results with the ADEOS-2/POLDER-2 and MODIS products are shown in Fig. 15(e). Note that the AOT $(0.5 \mu \mathrm{m})$ was derived from the retrieved AOT $(0.55 \mu \mathrm{m})$ and the AE. This event was also measured by the Skukuza AERONET station [white circle in Fig. 14(a)]. The instrument measured direct sun light and provided highly accurate AOTs as well as AE information. ${ }^{29}$ The lower right panel of Fig. 15(f) shows the AERONET-AOT $(0.5 \mu \mathrm{m})$ time series and AE before and after the BB event. The event started on August 19 and ended on

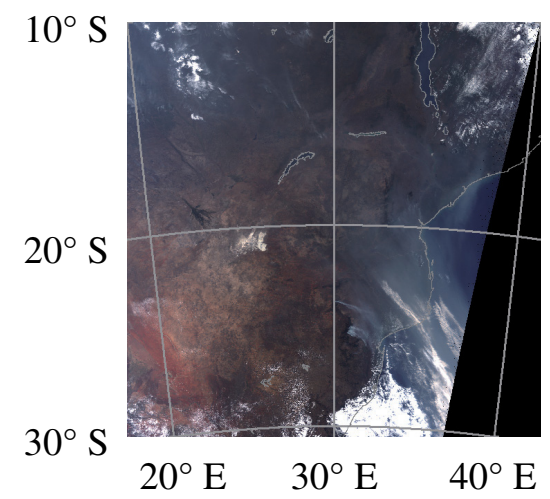

Fig. 14 True color composite image consisting of Terra/MODIS data (R:0.645, G:0.555, B:0.469 $\mu \mathrm{m}$ ); MOD021KM collection 6.1) captured on August 20, 2003, over southern Africa. 
Mukai, Sano, and Nakata: Algorithms for the classification and characterization of aerosols...

(a) AOT $(0.5 \mu \mathrm{m})$

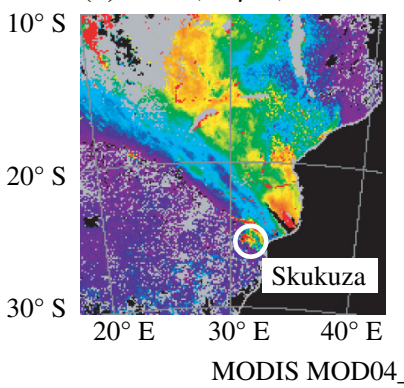

(c) AOT $(0.5 \mu \mathrm{m})$
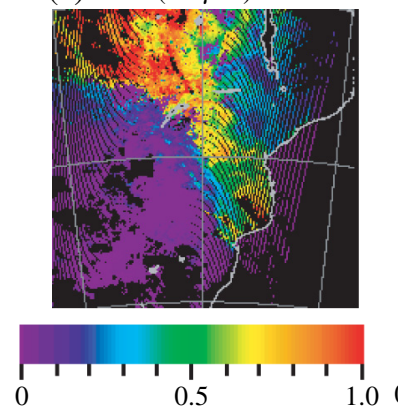

(b) Ångstrom exponent

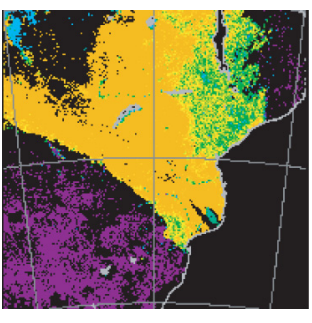

(d) Ångstrom exponent
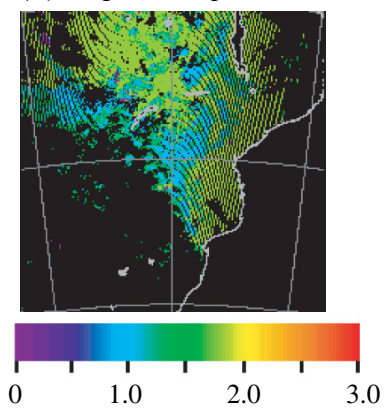

(e) Comparison of retrieved AOT with MODIS AOT

(f) AERONET Skukuza AOT $(0.5 \mu \mathrm{m})$ and AE (Ver. 3, Lev.1.5)
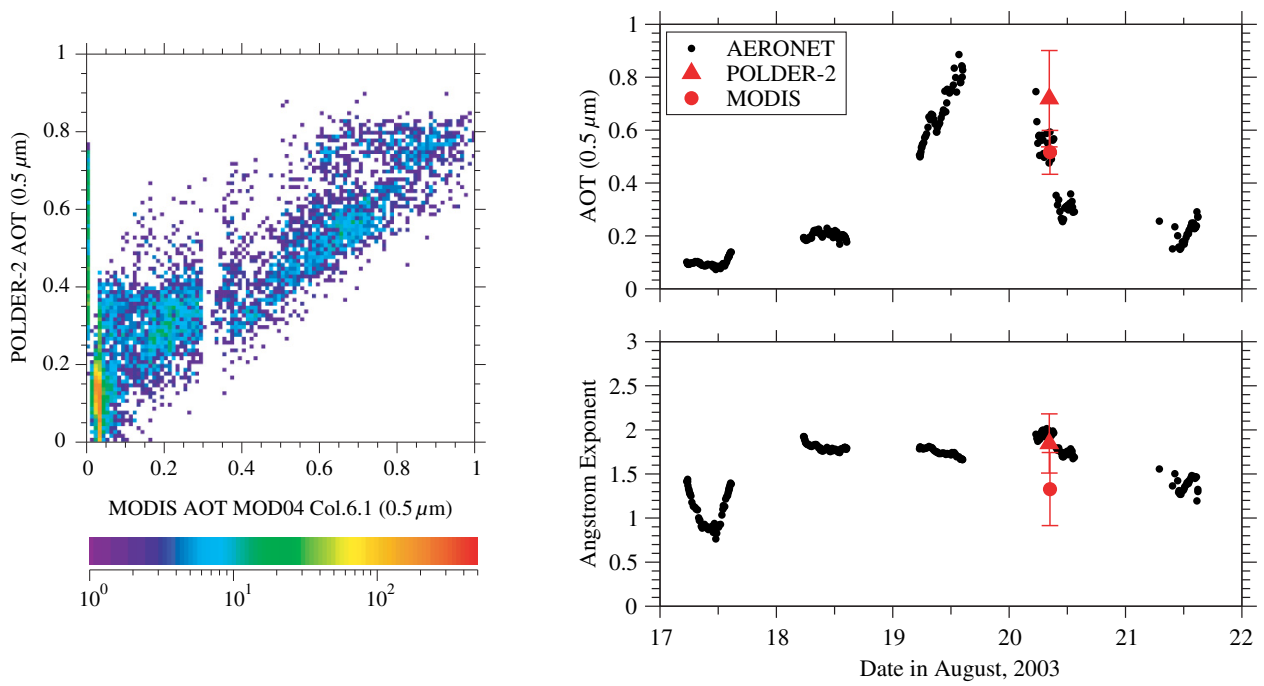

Fig. 15 (a) Retrieved distribution of the AOT $(0.5 \mu \mathrm{m})$ and (b) AE based on the MVRT simulation in a two-channel 0.670 and $0.865 \mu \mathrm{m}$ polarized radiance provided by the ADEOS-2/POLDER-2 over southern Africa on August 20, 2003. The Terra/MODIS products (MOD04_L2 Collection 6.1) are presented in (c) AOT $(0.5 \mu \mathrm{m})$ and (d) AE. The correlation between the AOT $(0.5 \mu \mathrm{m})$ retrieved results with the ADEOS-2/POLDER-2 and MODIS products are shown in (e). (f) The AERONETAOT $(0.5 \mu \mathrm{m})$ time series (in the upper graph) and AE (lower) before and after the BB event. The red triangles and the circles denote the retrieved value with the MRVT from the POLDER-2 and MODIS product, respectively.

the 20th. The red filled triangular symbols in Fig. 15(f) show the averaged AOT and AE values from POLDER-2 that passed over the station around 8:17 (UTC). The error bar for each symbol represents the standard deviation of the retrieved results within $\pm 0.1 \mathrm{deg}$ around the AERONET station. Our retrieved results maintained a $10 \%$ accuracy, over the Skukuza AERONET station. The retrieved results were comparable to the ground AERONET measurements. The red filled circles in Fig. 15(f) show the MODIS products as shown in Figs. 14(c) and 14(d). Compared with the AERONET measurements, the MODIS-AOT results were better than our POLDER-2 results, 
but our AE was better than the MODIS-AE. The aerosol retrieval algorithm used by MODIS is different from ours. The comparison of the results by different approaches with different data was considered more interesting than a validation.

\section{Summary and Future Outlook}

In summary of this study, the AAI for the detection of absorbing aerosols and the dust detection index (DDI) for discriminating BBAs from dust aerosols defined by Eqs. (1) and (2), respectively, were proposed based on almost all data observed by the ADEOS-2/GLI in 2003, and then the aerosol type classification criteria using these indices was developed. Further, it is of interest to mention that our classification criteria were applicable to cloud detections (refer to Fig. 10). As already mentioned in the preceding sections, several other systems have been proposed with respect to determining the AAI. Comparatively, our AAI or DDI indices take the simple form of just the ratio of the two-channel satellite measurements; therefore, they are easily applied to other satellite data. For example, the JAXA/GCOM-C/SGLI results will be available soon.

By first obtaining the aerosol types using the AAI and DDI, preparation of the aerosol models can be facilitated based on the satellite data before aerosol retrieval and this is especially useful for global-scale evaluations. Furthermore, if cloud detection is feasible even as simple and rough estimations, this becomes very useful for aerosol and cloud characterizations.

For the radiation simulation, we described a simplified aerosol model and provided effective algorithms for RT simulations with/without polarization fields for flexible aerosol characterizations. These are essential features for aerosol remote sensing from space at the global scale. By way of illustration, typical BBA case studies were considered using GLI and POLDER-2 measurements. The case study results, providing the BBA detection and characterizations, were examined using the Terra/MODIS-AOT (MODIS/MOD04_L2 Collection 6.1) and ground NASA/AERONET measurements.

The results obtained in this study are immediately applicable for data acquired from the JAXA/GCOM-C/SGLI launched on December 23, 2017. As mentioned previously, the SGLI has 19 observation channels including near-UV $(0.380 \mu \mathrm{m})$ and polarization channels. This study was aimed at providing efficient algorithms for aerosol retrievals utilizing the features of the SGLI measurements. Accordingly, the proposed AAI and DDI are suitable for use with the SGLI data. Moreover, the MVRT simulation method used in this study can be generally applied for the polarized radiation field.

This work is not only applicable to SGLI data analysis but is also intended to be valuable for other future missions. It is an upgrade in the efficiency of aerosol retrievals to acquire the aerosol types in advance as global-scale analyses and radiation simulations require long computation times for the various aerosol models at each satellite data pixel. It is important to have an initial rough overview of the aerosol distributions, and therefore, prior information about aerosol types can be useful. The aerosol model determines a single scattering pattern, and the structure of the atmosphere should be taken into account during multiple scattering simulations of the Earth's atmosphere-surface system. The real aerosol and atmosphere are not easy to deal with in Sec. 4.1. Even paying attention only to the former, there are still difficult problems to consider, such as the heterogeneity of components, the determination of various sizes, and the nonspherical shape of aerosols. These properties vary vertically and the amount of aerosols depends also on the altitude. On the other hand, the optical sensors of the satellite observe the reflectance at the top of atmosphere, and hence they catch the radiation accumulated from the whole atmosphere. Since both GLI and SGLI are optical sensors that observe the Earth from one direction only, it is impossible to directly obtain the vertical information regarding the atmosphere. However, complex aerosol layering and aerosol-cloud layering exist in nature. For an example, the lofted dust mixed with some smoke was observed over Japan in early spring above a highly polluted boundary layer characterized by urban haze. It is possible to numerically solve an RT problem in the multilayer atmosphere model, but only after understanding in detail the real atmospheric vertical structure. Nevertheless, we can affirm that the one-layer atmosphere model composed of simple aerosol model adopted in Sec. 4.1 is certainly too simple to describe the real aerosols. In order to solve this issue, complex and multiperspective data assimilations are necessary. Therefore, the 
combined use of multiangle or multisensor satellite data, lidar observations from space and ground, and numerical model simulations should be taken into account. A naturally iterative process will be continuously followed. It takes long processing time, especially in the global scale. The assimilation work of SGLI data, regional numerical model simulations, and ground measurements has just started and presently restricted over the territory of Japan. However, the results of our study indicate that AAI and DDI indices can be very efficiently used for a quick estimation and first approximation of the aerosol model.

The AAI and DDI thresholds for clouds presented here should be further confirmed. It would be significant for the detection of clouds or aerosols, the analysis of aerosols over clouded areas, or the interaction of aerosols and clouds. ${ }^{43,44}$ In order to gain insights into this complicated issue, more data and detailed treatments should be examined. These studies are challenging and require additional research outside the scope of the current study. Future studies should consider the following:

1. more precise cloud detection;

2. nonspherical aerosol shapes, particularly for dust;

3. evaluation of the aerosol influence on Earth's radiation budget;

4. combined use of multisensor measurements;

5. complex aerosol layering and aerosol-cloud layering through multidata assimilations.

\section{Acknowledgments}

The authors thank Mr. M. Maeda, Mr. T. Fujito, and Dr. M. Yasumoto for their help preparing the satellite data, NASA for distributing the MODIS and AERONET data, and JAXA for the ADEOS-2 data. This work was supported in part by the Global Change Observation Mission Climate project by JAXA (No. JX-PSPC-434796). It was also supported by the Global Environment Research Fund of the Ministry of Environment, Japan (S-12).

\section{References}

1. R. Kahn, "Reducing the uncertainties in direct aerosol radiative forcing," Surv. Geophys. 33, 701-721 (2012).

2. IPCC, "Climate Change 2013: the physical science basis. Contribution of Working Group I to the Fifth Assessment Report of the Intergovernmental Panel on Climate Change," p. 1535, Cambridge University Press (2013).

3. T. Littmann, "Dust storm frequency in Asia: climatic control and variability," Int. J. Climatol. 11, 393-412 (1991).

4. S. Kinne et al., "Monthly averages of aerosol properties: a global comparison among models, satellite data and AERONET ground data," J. Geophys. Res. 108(D20), 4634 (2003).

5. M. Nakata, I. Sano, and S. Mukai, "Air pollutants in Osaka (Japan)," Front. Environ. Sci. 3, 18 (2015).

6. M. Nakata et al., "Seasonal and regional characteristics of aerosol pollution in east and southeast Asia," Front. Environ. Sci. 6, 29 (2018).

7. O. Torres et al., "Derivation of aerosol properties from satellite measurements of backscattered ultraviolet radiation: theoretical basis," J. Geophys. Res. 103, 17099-17110 (1998).

8. I. Chiapello et al., "Detection of mineral dust over the North Atlantic Ocean and Africa with the Nimbus 7 TOMS," J. Geophys. Res. 104, 9277-9291 (1999).

9. O. Torres et al., "Aerosols and surface UV products from OMI observations: an overview," J. Geophys. Res. 112, D24S47 (2007).

10. J. Deuzé et al., "Remote sensing of aerosols over land surfaces from POLDER ADEOS-1 polarized measurements," J. Geophys. Res. 106, 4913-4926 (2001).

11. F. Waquet et al., "Retrieval of aerosol microphysical and optical properties above liquid clouds from POLDER/PARASOL polarization measurements," Atmos. Meas. Tech. 6, 991-1016 (2013). 
Mukai, Sano, and Nakata: Algorithms for the classification and characterization of aerosols...

12. S. Mukai et al., "Multiple scattering in a dense aerosol atmosphere," Atmos. Meas. Tech. Discuss. 5, 881-907 (2012).

13. S. Mukai, I. Sano, and T. Takashima, "Investigation of atmospheric aerosols based on polarization measurements and scattering simulations," Opt. Rev. 3(6), 487-491 (1996).

14. N. Hsu et al., "Detection of biomass burning smoke from TOMS instruments," Geophys. Res. Lett. 23, 745-748 (1996).

15. O. Torres, H. Jethva, and P. Bhartia, "Retrieval of aerosol optical depth above clouds from OMI observations: sensitivity analysis and case studies," J. Atmos. Sci. 69, 1037-1053 (2012).

16. J. Flores et al., "Evolution of the complex refractive index in the UV spectral region in ageing secondary organic aerosol," Atmos. Chem. Phys. 14, 5793-5806 (2014).

17. I. Sano et al., "Retrieval algorithm based on combined use of POLDER and GLI data for biomass aerosols," J. Remote Sens. Soc. Jpn. 29(1), 54-59 (2009).

18. S. Mukai et al., "Role of near ultraviolet wavelength measurements in the detection and retrieval of absorbing aerosols from space," Proc. SPIE 10424, 104240X (2017).

19. M. de Graaf et al., "Absorbing aerosol index: sensitivity analysis, application to GOME and comparison with TOMS," J. Geophys. Res. 110(D1), 16,911-16,921 (2005).

20. TOMSEPL2, "TOMS earth-probe ozone (O3) total column 1-orbit L2 Swath $50 \times 50 \mathrm{~km}$ V008," NASA/GSFC (Code 614) (1996).

21. S. Mukai et al., "A study of aerosol pollution episode due to agriculture biomass burning in the east-central China using satellite data," Front. Environ. Sci. 3, 57 (2015).

22. J. Herman et al., "Global distribution of UV-absorbing aerosols from Nimbus-7/TOMS data,” J. Geophys. Res. 102, 16911-16922 (1997).

23. P. Ciren and S. Kondragunta, "Dust aerosol index (DAI) algorithm for MODIS," J. Geophys. Res. 119, 4770-4792 (2014).

24. I. Lensky and D. Rosenfeld, "Clouds-aerosols-precipitation satellite analysis tool (CAPSAT)," Atmos. Chem. Phys. 8, 6739-6753 (2008).

25. S. Mukai, I. Sano, and M. Nakata, "Discrimination and retrieval of aerosol types using multi-channels including near-UV and polarization for GCOM-C/SGLI," Proc. SPIE 10776, 1077616 (2018).

26. T. Eck et al., "Wavelength dependence of the optical depth of biomass burning, urban, and desert dust aerosols," J. Geophys. Res. 104(D24), 31333-31349 (1999).

27. N. O'Neill, O. Dubovik, and T. Eck, "Modified Angstrom exponent for the characterization of submicrometer aerosols," Appl. Opt. 40, 2368-2375 (2001).

28. N. O'Neill et al., "Spectral discrimination of coarse and fine mode optical depth," J. Geophys. Res. 108, 4559 (2003).

29. B. Holben et al., "AERONET: a federated instrument network and data archive for aerosol characterization," Remote Sens. Environ. 66, 1-16 (1998).

30. O. Dubovik et al., "Variability of absorption and optical properties of key aerosol types observed in worldwide locations," J. Atmos. Sci. 59, 590-608 (2002).

31. A. Omar et al., "Development of global aerosol models using cluster analysis of Aerosol Robotic Network (AERONET) measurements," J. Geophys. Res. 110, D10S14 (2005).

32. S. Mukai, I. Sano, and M. Nakata, "Improvement of retrieval algorithms for severe air pollution," Proc. SPIE 10008, 1000811 (2016).

33. P. Chýlek and V. Srivastava, "Dielectric constant of a composite inhomogeneous medium," Phys. Rev. B 27, 5098-5106 (1983).

34. T. Bond, G. Habib, and R. Bergstrom, "Limitations in the enhancement of visible light absorption due to mixing," J. Geophys. Res. 111, D20211 (2006).

35. T. Bond and R. Bergstrom, "Light absorption by carbonaceous particles: an investigative review," Aerosol Sci. Technol. 40, 27-67 (2006).

36. M. Balarabe et al., "Monthly temporal-spatial variability and estimation of absorbing aerosol index using ground-based meteorological data in Nigeria," Atmos. Clim. Sci. 6(3), 425-444 (2016).

37. C. Bohren and N. Wickramasinghe, "On the computation of optical properties of heterogeneous grains,” Astrophys. Space Sci. 50, 461-472 (1977).

38. K. Fuller, W. Malm, and S. Kreidenweis, "Effects of mixing on extinction by carbonaceous particles," J. Geophys Res. 104(D13), 15941-15954 (1999). 
39. A. Sayer et al., "AERONET-based models of smoke-dominated aerosol near source regions and transported over ocean, and implications for satellite retrievals of aerosol optical depth," Atmos. Chem. Phys. 14, 11493-11523 (2014).

40. S. Mukai, M. Yasumoto, and M. Nakata, "Estimation of biomass burning influence on air pollution around Beijing from an aerosol retrieval model," Sci. World J. 2014, 1-10 (2014).

41. I. Sano, "Optical thickness and Angstrom exponent of aerosols over the land and ocean from space-based polarimetric data," Adv. Space Rev. 34, 833-837 (2004).

42. F. Bréon et al., "Polarized reflectance of bare soils and vegetation: measurements and models," IEEE Trans. Geosci. Remote Sens. 33, 487-499 (1995).

43. F. Peers et al., "Absorption of aerosols above clouds from POLDER/PARASOL measurements and estimation of their direct radiative effect," Atmos. Chem. Phys. 15, 4179-4196 (2015).

44. H. Jethva et al., "Validating MODIS above-cloud aerosol optical depth retrieval from "color ratio' algorithm using direct measurements made by NASA's airborne AATS and 4STAR sensors," Atmos. Meas. Tech., 9, 5053-5062 (2016).

Sonoyo Mukai is a professor at the Kyoto College of Graduate Studies for Informatics. She received her $\mathrm{PhD}$ in science from Kyoto University in 1974. Her current research interests include light scattering by small particles, radiative transfer, and atmospheric physics. She is a member of SPIE and AGU.

Itaru Sano is a professor at Kindai University. He received his $\mathrm{PhD}$ in computer science from Kanazawa Institute of Technology in 1997. His current research interests include aerosol remote sensing using both space- and ground-based systems. He is a member of SPIE and AGU.

Makiko Mukai is an associate professor at Kindai University. She received her PhD in Earth and planetary physics from the University of Tokyo in 2007. Her current research interests include model simulations and air pollutions. She is a member of AGU. 